\title{
University of Melbourne
}

\author{
Kay Are
}

Touching stories: Objects, writing, diffraction and the ethical hazard of self-reflexivity

\begin{abstract}
:
This article takes up Donna Haraway's discussion of 'diffraction' as a remedial to the literal self-centredness of the figure of reflection, in order to propose an alternative learning objective for creative writing curricula. There, currently, 'reflective learning' is a common if implicit objective, often manifesting in the form of journal-keeping and some kinds of writing exercises, while a capacity for 'reflection' can be seen at least bureaucratically to validate the existence per se of university writing programs (Green \& Williams 2018). In the educational literature, self-reflexive contemplation of one's own experiences is said to be preliminary to the achievement of deep, life-long and transformative knowledge (Ryan \& Ryan 2012). But, from a posthumanist standpoint, the discourse around reflection in the Scholarship of Teaching and Learning appears ideologically committed to a subjectivity that is integral, insular and (thus) humanist, and constitutionally resistant to transformation. Here, I make use of the post-secondary educational literature on 'object-based learning' (OBL) to suggest that students' touching of objects can be conducive to diffractive rather than reflective learning - that is, conducive to learning that avoids the humanist atomisation of subject from object and instead entails establishing one's interconnectedness with environments. To this end, I propose a way to frame OBL activities as developing a reciprocal relationship between writing subjects and objects of study, in which students situate their writing not as a reflection on/of objects 'out there' in the world, but rather as an active and literal co-creation of the self-as-world.
\end{abstract}

\section{Biographical note:}

Kay Are is a writer and researcher with interests in multimodal and siteresponsive writing; in writing theory and pedagogy; and in posthumanist, feminist and materialist takes on all the above. Collaborations and discussion welcome: kayr@unimelb.edu.au

\section{Keywords:}

creative writing - reflective learning - object-based learning (OBL) diffraction 
'Understanding the world is about living inside stories. There's no place to be in the world outside of stories. And these stories are literalized in [...] objects [...]. Or better, objects are frozen stories.'

- Donna Haraway (2000: 107)

\section{Introduction}

This article looks at, or holds onto, touch as a research method - and, importantly, as a method that can be used in creative writing classrooms to catalyse what I want to call, after Donna Haraway, 'diffractive learning'. With this term, I wish to contribute to modifying the discourse around what is known as 'reflective learning', where a student's self-reflexive consideration of their own experiences is considered preliminary to the achievement of deep and transformative knowledge (Ryan \& Ryan 2012). This approach commonly manifests in creative writing curricula in the form of journal-keeping and other writing exercises that invite students to be attentive to, to recall and to document their personal reactions to nominated experiences, with a view to rendering these experiences available for incorporation into creative work (Haseman \& Mafe: 219-221; Barton \& Ryan 2014). I do not contest the productiveness of such exercises; rather, I am concerned here to trouble some of the presuppositions attached to the discourse of reflection as it appears in the Scholarship of Teaching and Learning and which therefore risk passing surreptitiously into Creative Writing classrooms. I observe in the literature an unmarked ideological commitment to a subjectivity that is integral, insular and (thus) humanist - qualities that, by the lights of this reader's posthumanism, delimit the nature of the very transformation that reflective learning is said to occasion. Truly transformative learning, I argue below, must avoid the humanist atomisation of subject from object in favour of establishing students' interconnectedness with their environments. But my ultimate intention in what follows is constructive rather than critical: I take seriously Donna Haraway's discussion of 'diffraction' as a remedial to the literal selfcentredness of the figure of reflection and I propose a mode of diffractive writing practice to demonstrate the possibility of a counterpoint to self-reflection. Namely, I will here augment the concept of 'object-based learning' (OBL) in order to suggest that diffractive learning can result from framing students' tactile engagement with objects in the classroom as the development of reciprocal relationships between writing subjects and objects of study.

The research project, of which the present article is an extension, wonders about the role touch plays in writing about, and in, 'the Anthropocene'. [1] How might one's writing about a thing be - or how might it be brought to be - affected by one's impression of it, by which I mean one's lively, present sense of being impressed by a thing; of feeling its touch, of feeling in response to it? (For the sakes of simplicity and accessibility to an interdisciplinary audience, I here use 'object', 'thing' and 'entity' without discrimination - though the agential flavour of 'thing-based learning' would perhaps do more to bolster my argument (see Bennett 2010: xvi-xvii)). What can happen differently - to writing; to objects; to what we learn from writing and objects - when writing and object-touch are undertaken simultaneously? These questions are underpinned by the characteristic presupposition of the Environmental Humanities that in complex ways all entities 'become in consequential relationship with others' (van Dooren et al. 2016: 3). One way in which this presupposition manifests is as a concern to situate writing not as a reflection on/of objects 'out there' in the world, but rather as a practice of 'worlding', that is, as an ontologising practice through which subject and object become co-implicated or, better, co-become (Barad 2007; Kirby 2011; Neimanis 2017; Mauthner 2016; Somerville et al. 2011). The old idea that people and things historically and materially co-become is currently articulated from at least three distinct scholarly bases. First, 
Material Ecocriticism (Iovino \& Oppermann 2014) and Multispecies Studies (van Dooren et al. 2016) acknowledge by comparable means the passionate co-implication of species, and both create concepts with which to probe the act of writing as a recounting or taking-account of life stories that are both greater than and entangled within human biography (see also van den Hengel 2012). Second, Ecological Marxism postulates that the invention and approaching exhaustion of nature is historically entwined with the unfolding enterprise of capital, whose installation of successive regimes of social property relations has regulated human societies, precisely vis-à-vis the management of human dispositions towards 'nature' (Moore 2016). Third, quantum field theory suggests the continual becoming co-implicated of particles is very literally the continual invention of existence (Barad 2012). Karen Barad's (2017; 2012) feminist reading of the science energises Marxist and empirical forms of materialism alike, and thus presents an opportunity to unite these three bodies of scholarship.

\section{Object-based learning}

Channelling these multi-disciplinary threads into the more specific arena of writing pedagogy generates my interest in OBL, a teaching praxis that advocates the benefits to learning of students' sensory engagement with objects. When Donna Haraway (2000) said that objects are frozen stories, she foretold something like OBL's core assumption, which is that embodied exposure to artefacts, specimens, artworks and like matter is a means to acquiring an understanding of the social, historical, political and economic contexts that accrete in these objects, and from which these objects are extracted (Chatterjee, Hannan \& Thomson 2016). (The conditions of extraction and of re-presentation in institutional settings tell a story of their own, it bears noting.) In the scholarship of teaching and learning, OBL is considered effective not because objects are expedient conveyers of knowledge per se, but rather because they engender in learners a preliminary will to acquire knowledge (Hein 2009; Chatterjee, Hannan \& Thomson 2016). Objects - suffused with the exquisite particularity of the circumstances of their manufacture, circulation and abandon - are said to stimulate student inquiry, experimentation, inference and the formulation of research questions, and to provide impetus for collaborative problem-solving (Hein 2009; Alvarado \& Herr 2003). The pursuit of answers to self-generated questions is said to bring students to formulate new ideas about the world, ideas which become the knowledge that constructs a world view - to formulate, in other words, their learning. Learning from objects appears to rely on a combination of the initial and intentional mystification of an object's provenance and of its relationship to intended learning outcomes; on learners' curiosity; and on learners' bodily engagement through one or more of their senses.

I don't disagree that OBL is a productive pedagogy. In the creative arts, the fecundity of instrumentalising sense engagement to stimulate new work is evidenced by a rich ekphrastic tradition. [2] Anecdotally, I have witnessed highly creative ekphrastic responses to objects when I have taken my own students to mine the Germaine Greer archive, the Tiegs Museum's zoology collection and many exhibitions at the George Paton Gallery, all at the University of Melbourne; I have also brought everyday objects into classes to prompt writing activities. However, firstly, I am not inclined to take productivity as a valid measure of a pedagogy's success. I am persuaded by Tony Fry, who invokes Félix Guattari to argue that confronting ecological debts requires 'the development of new kinds of socio-environmental subjects (new kinds of people) rather than increased productivism (the means of exchange by which existing social subjects are replicated and their world extended)' (Fry, quoted in Armstrong 2009: 189). Secondly, I disagree with the striking view, in the literature on OBL as with that on ekphrasis, that touching objects rather than simply viewing them is gratuitous or beside the point. This view is not mysterious if we recall that the provenance of OBL is in museology, the entwinement of whose history with ocular-centric art-historical discourses long ago 
rendered the museum a primarily 'optical instrument' disparaging of touch, and of the touch of a non-connoisseur public in particular (Candlin 2010; Meecham 2016). But, contra this tendency, my position is that object-touching is important because it can occasion a mode of learning able to avoid the pitfalls of reflective learning that I will identify below. What is more, seeking opportunities to de-centre reflective learning is, I hold, vital to those of us who teach writing, given that reflective learning is a cornerstone of the constructivist models of education that are widely accepted and practiced in Western tertiary settings (Ryan \& Ryan 2012: 244) - no less within the discipline of Creative Writing.

\section{Constructivist, experiential and reflective learning}

It should be said at this point that the very idea that learning could be fostered by activities such as student-generated inquiry, problem-solving and experimentation defines a constructivist approach to education (Dewey 1998; Kolb \& Fry 1975). Constructivism takes as tacit the idea that 'learning' is not adequately defined as the absorption of pre-existing facts; a learner instead rolls received facts into their personal construction of a picture of the world, which is interminably moulded by lived experiences. This is pedagogy as 'knowledge transformation rather than knowledge transmission' (Ryan \& Ryan 2012: 246). Constructivism thus positions itself as able to catalyse genuinely transformative learning. The educator's role in such a scenario is to expose students to novel settings and data, and to administer modes and degrees of guidance and feedback (and, presumably, to teach the skills for receiving and utilising guidance and feedback) during the course of a student's pursuit of the enquiries that arise from said exposure to novelty (Kalantzis \& Cope 2008). A subset of constructivism is experiential learning, which centres on 'primary experience, that is [...on learning] through sense experiences' (Jarvis 1995: 75). In experiential learning, sense experience is taken either to include the embodied apprehension of verbal communication, of the kind that takes place, for instance, in lectures (Jarvis 1995), or to refer more exclusively to non-verbal somatic encounters (Mathews 1998). David Kolb and Roger Fry (1975) attribute the capacity to learn from primary experience to a learner's passing through cyclic phases, alternating between lived experience, abstracted reflection on experience and the application to new experience of insights gained through reflection (Smith 2001). Other theorists have since nuanced the model to qualify degrees of reflection (Grossman 2008), to remark on the complexity of reflection as practice (Bain et al. 2002) and to problematise the testing of reflective-learning outcomes (Ryan 2013). Thus, the educator is persistently implored - in experiential modes diverse as OBL, inquiry-led learning, problem-based learning and collaborative learning, among others - to factor in opportunities for student 'reflection' or 'reflexivity' (Bozalek \& Zembylas 2017: 112).

Closer to home, reflection is a pivot in the version of experiential learning that Hazel Smith and Richard Dean influentially described as 'the iterative, cyclic web' (2009) of research-led practice/practice-led research. Here, as the practitioner moves iteratively between creative experimentation, academic labour and publication/performance, it is reflection on insights accrued from one activity that enables these insights to inform decision-making about the next (Smith \& Dean 2009: 19-21). In a more bureaucratical sense, reflection has been shown to be that aspect of practice-based research that defines and even legitimates creative writing's place in the university context, at least in the UK (Green \& Williams 2018). Similarly, journal writing is registered as a learning modality thanks to its capacity to enable reflection (Moon 2004). That said, there are ways to go about it that are more or less gainful for students of Creative Writing, as Nike Bourke and Philip Nielsen point out. These authors suggest that journal writing will contribute to learning in Creative Writing to the extent that it promotes self-reflexive engagement 'not only with the moment of writing, but the moments between writing - the ongoing, reflective, critical and analytical learning process of "being a writer" 
(2004). In other words, reflection in writing works for learning insofar as it prompts the making of connections between experiences in a way that binds the student's identity as writing practitioner.

What is the phenomenological and ontological character of reflection, though? And, given the visual metaphor on which it turns, what is the political character of reflection in a context already marked, as I have noted, by the ocular-centric derision of touch? The answer to this question will vary according to the extent to which it is considered problematic that a manufactured 'reflection' will only partially capture the writer and the societies and environments in which she is embedded. Many educational theorists, for their part, suggest that fractional capture is not merely an inescapable part of learning but, indeed, the pathway towards it: the selective assimilation of numerous and disparate experiences into a cohesive logic or meaning is given as the mechanism by which reflective learning can occur (Boud, Keogh \& Walker 1985: 16). More specifically, reflection, first, allows students to 'make sense of' experiences by requiring them to interpret, consolidate and pattern them meaningfully (British Further Education Curriculum and Development Unit, quoted in Boud, Keogh \& Walker 1985: 13). Second, and importantly, reflection requires that 'meaningfully', in the previous sentence, be defined by the student, who will select experiences to bring to order on the basis of personal priorities, rather than on the basis of externally contrived rewards and punishment (Sansone \& Harackiewicz 2000). Accordingly, if reflective activities prompt learning that is more transformational and durable than rote learning, educational theory says this to be because reflection is a function of individual psychology, wherein connections between discrete learning experiences are both uncovered and contrived. The remainder, or what eludes capture, is important to constructivist learning theory only in the sense that its excision provides learning's definition. [3]

But I want to insist that if learning from reflection proceeds by actualising a systematised subjectivity - if learning equates merely to representing a self to the self by means of semiotic abstraction from material-discursive environments - then reflective writing cannot offer any greater 'transformation' than the progressive consolidation of a subject who is given no cause to disturb or notice its founding assumptions. Certainly, converting lived experience to episodic representation via iterative experimentation is a learnt skill of obvious advantage across the creative arts (Barton \& Ryan 2014). The teaching of such a skill, however, is invariably political. Elsewhere (Rozynski 2012; Rozynski 2015), I have urged a view of writing pedagogy as ethical practice, in light of the Cartesian relationship with materiality taught through Creative Writing's 'hidden curriculum' (Rozynski 2012; Rozynski 2015). I would now add that an ethics of writing may be best defined as part of a wider project in which we must '[learn] how to inherit colonised and ecologically challenged lifeworlds' (see Taylor et al 2016: 129). It may best be enacted, accordingly, by nurturing and negotiating a mutual dependency between pedagogy, creative practice and consciousness of the environments in which an instance of writing is enmeshed. ('Environments' has the disadvantage of seeming to point to 'the Natural', while in fact I refer here to the collective phenomenological, technological and 'naturalcultural' (Haraway 1992) matter that comprises ontology in toto.) Considering the intra-relationships that define human life as always morethan-human, transformation of the self will always simultaneously entail a transformation of environments (van Dooren et al. 2016; Barad 2012). Thus, one result of interpreting the learning subject as singular and alienable, as a closed circuit, is the severe restriction of students' ability to challenge the exploitative assumptions subtending Anthropocenic relationships between humans and extra-human nature. A discourse of humanist selftransformation not only declines to take account of one's many material and extra-human debts, it is also unable to provide grounds for assuming responsibility for the material worlds 
that transformative learning effects as a world-making practice. Nor can it exploit the creative affordances of a view that positions transformative learning as world-making. Illustrating one way in which these responsibilities and affordances might manifest in Creative Writing is my objective in the remainder of this paper.

\section{Diffraction}

Writing is a representational practice and therefore not one learning behaviour among many (questioning, listening and storing are examples of non-representational learning behaviours). Rather, writing is a technology of particular importance in the development of human/extrahuman relationships. This is partly because forms of representation have particular power to bend and re-shape discourse, and partly because, given the historical exercise of such power, it is arguably incumbent on those who would wield representational technologies to become aware of the effects of the discourses they have fostered to date. Haraway's skewering of techno-political representational practices (1992) elucidated the material-discursive means by which, in the 1980s and 90s, the natural and reproductive sciences constructed the docility of objects ('nature', 'the maternal environment', 'the foetus') at the same time as they legitimated the right of the (scientific) expert to speak on their behalf. Haraway avers that articulatory practices - of which writing is exemplary - work to authorise certain subjects to 'speak as if they were the mouthpiece for the speechless objects that they have just shaped and enrolled as allies' (1992: 312), in a logic of subjugation that, as she notes, Edward Said first observed of Orientalism. Others (Barad 2007; Kirby 2011) more recently draw support from Haraway to contend that, far from one mechanism of discursive subjugation among others, writing in fact exists as a more generalised economy; writing is the Earth articulating itself into forms, 'natural' and 'cultural' alike: 'Culture - cultural texts, human capacities, writing, neural pathways in human brains - are all instances of Nature writing itself' (Neimanis 2017: 184). The idea that the Earth might instrumentalise human beings and their representational technologies, such as literary texts, to power its own self-investigation (Kirby 2011) renders a more complex picture of writing as a subjugating articulatory practice. It is a picture that attributes more complexity and perhaps ambivalence to the writer's representational responsibility, but in no sense abrogates the ethical call to confront it. As Neimanis notes, the idea that "Nature writes itself" offers no absolution' (2017: 194). Rather, it wagers that representation is not 'a way of capturing or speaking for that which is ontologically separate, but instead always a case of iteration of the matter of writing' (195, added emphasis). Every act of writing, as it concretises as one of Earth's forms, testifies to the materials and environments from which it emerges and of which it is an expression. This suggests that the matter about which we write is 'morphologically active, responsive, generative, and articulate' (Barad, quoted in Bozalek \& Zembylas 2017: 116). 'Reflection' is 'implicitly based on the phenomenon of a pattern of light that reflects an actual object or entity' (Davies, quoted in Bozalek \& Zembylas 2017: 117). It is clearly inadequate to such mutable and agential matter.

But how might students be prompted to recognise and learn from this thinking? The question returns this paper to the politics of evoking a visual metaphor as a vehicle for pedagogy. As McHugh (2007) notes, Haraway has observed that reflecting on the self presupposes that 'one can recognise and identify one's own cultural biases'; it assumes 'a transparency of self that does not exist' (27). Haraway urges the subversive substitution of reflection with diffraction, a figure whose utility lies in the way it redeploys optics into a model of creativity that doesn't equate representation with mere reproduction of the same (1992: 295). As an empirical phenomenon, diffraction points to the behaviour of waves (photons, as much as waves at sea, 
radio waves, and so on) when they encounter and intercept obstacles and each other. At the moment of contact, waves physically recalibrate each other, each redirecting the other into a diffractive pattern in which 'both' 'subject' and 'object' are absorbed and remade (Geerts \& van der Tuin 2016; see Barad 2007: 74-85 for a detailing of the physics). The first point to note is that the simultaneous, reciprocal exercise of the agency of each wave on the other problematises the allocation of subjectivity or objectivity to either one; second, the waves reconstitute on contact as a singular novel pattern, such that they can be said post-contact to constitute one internally inextricable entity rather than two discreet entities conjoined. Diffraction's 'optical features are set to produce not effects of distance, but effects of connection, of embodiment, and of responsibility' (Haraway 1992: 295). Against reflection's presumption of an entity whose identity is fixed prior to its representation, diffraction presumes that objects, too, contribute to constructing a new, diffracted entity; unlike reflection, that is, diffraction 'is a process of producing difference' (Bozalek \& Zembylas 2017: 117). Figuratively, then, reflection is to representation as diffraction is to generation: whereas 'representation depends on possession of a passive resource, namely, the silent object, the stripped actant' (Haraway 1992: 313) in order to produce a copy of the passive resource 'in the sacred image of the same' (299), generation allows for an iteration of the resource that draws difference into composing interference patterns, thereby issuing in unforeseeably novel forms (299):

Diffraction does not produce 'the same' displaced, as reflection and refraction do. Diffraction is a mapping of interference, not of replication, reflection, or reproduction. A diffraction pattern does not map where differences appear, but rather maps where the effects of difference appear. Tropically [...] the first invites the illusion of essential, fixed position, while the second trains us to more subtle vision. (Haraway 1992: 300)

Haraway proposes diffraction as a critical research practice - a way to 'study the practices of knowing as they are enacted in the materiality of the world, in a state of interdependence with other parts of the world' (Bozalek \& Zembylas 2017: 118). But my interest here is in coding as diffractive the spaces of writing and writing pedagogy. If diffractive research would involve, as Haraway suggests, 'paying attention to 'the interference patterns on the recording films of our lives and bodies' (quoted in Geerts \& van der Tuin 2016), then I would similarly frame diffractive learning as learning how bodies and objects are and can be responsive to other bodies and objects, and how they might better respond: a practice of learning how one (who is always more-than-one) might cultivate the conditions within their environment for coflourishing (van Dooren et al. 2016: 17). This framing work is performed below through the prism of OBL.

\section{Towards diffractive OBL}

Diffraction yields an alternative conceptualisation of object-engagement; I now return to consider how this conceptualisation might further OBL's development as a diffractive pedagogy. The move expedites OBL's relocation from museology into educational fields such as pedagogies of place (Somerville et al. 2011), new materialist pedagogies (Snaza et al. 2016) and the broad category that Jonathan Mathews (1998) called 'somatic learning', where this is defined not as (cerebral) learning occasioned by embodied contact, but rather as the body's learning: as the student's felt change in relation to an object touched (Dudley 2012; Chatterjee 2008).

The growing scholarship on diffraction as a methodology values the way that it, first, recognises the ontologising power of discourse, and, second, affords agency to matter - or, translated into (diffracted with) an OBL vocabulary, the agency of objects. First, then: writing diffractively in response to engagement with objects would, as Natasha Mauthner says of 
other diffractive practices, seek to 'account for [writing's] non-innocent metaphysical specificity and that of the phenomena [it can] intra-actively produce, [...] by accounting for [writing's] own ontological existence and for the role [it plays] in materialising the ontology of [its] objects of study' (2016). Through and through discursive, writing is also ontologising: in the words of Thom van Dooren et al., 'ways of knowing and understanding have profound consequences: they shape worlds' (2016: 12). Discourse concretises as environments that inhibit or enable transformations of discourse - and these environments inhibit and enable unevenly. The endpoint of aggregating diffractive concepts to OBL scholarship might lie in the recruitment of new student-object conglomerate entities into world-making, that is, into harnessing writing towards materially altering configurations of power. Diffractive writing would be a mode of enquiry through which we 'ask how specific [world-makings] come to matter, and to matter differently, for given beings' and objects (van Dooren et al. 2016: 13; see Rozynski 2015 for examples of creative texts born of this objective). In itself, attempting to maintain a grasp on writer-object co-implication in practice implies a level of difficulty the very negotiation of which might '[open] up the frames of what registers to us and so what matters to us' (Wright 2014: 279).

Second, as per Barad's observation that the diffractive metaphor surfaces in scientific research as a will to 'not hold one set of concerns as pre-existing or stable or primary over another' (quoted in Mauthner 2016), diffractive writing refrains from affirming a pre-existing, stable or primary self vis-à-vis the representation of objects, in favour of dispersing the self vis-à-vis its interaction with objects. Diffractive writing would allow the interrelations between things (between the writing 'subject' and its 'objects') to pattern composition. In other words, the point of diffractive OBL is not to manufacture a story about or for objects, but rather to inscribe the co-implication of the biographies of object and student - a co-implication that is phenomenological as much as it is discursive, and a biography that is generated by object and student alike at the moment of connection. Diffractive writing would produce texts that give accounts of the one as multiple, that refuse to map subject-object differentiation from an impossibly objective standpoint, and that refuse to draw objects into a dialectic relationship with a posited self. Writing towards diffractive learning can thus be said to be a way of exploring and co-constructing a history for objects that is also an autobiography. The points at which the writer's and the object's histories intercept each other, and the points of difference in the writer's and object's coming to matter: these provide narrative nodes that string together into constructed histories. Noticing points of connection acknowledges that 'both forms of life are shaped and made possible through a shared heritage, an entanglement that Isabelle Stengers characterises as "reciprocal capture"' (van Dooren et al. 2016: 3). Such stories would resist viewing extra-human others 'as mere symbols, resources, or background for the lives of humans' (van Dooren et al. 2016: 6).

That the work of discerning connection with objects should be performed through touch is an important final consideration. Barad's elucidation of quantum field theory endorses a view of diffraction as a necessarily tactile practice. Crudely described, to position one or other of the particles comprising an entity as 'the touching particle' and another as 'the touched particle' is nonsensical. This is because the quantum interpretation holds touch not to be a question of one entity affecting another, as per classical cause-and-effect, subject-object mechanics, but a matter of mutual touch effecting a wholly new entity. Further, quantum physics specifies that upon touch, thanks to the quirks of non-linear time, the new entity has always been the one conjoined entity. Touching another is therefore always at the same time self-touch. Touch is, on one, spooky level, literally transformative, re-aligning particulate configurations into liaisons more ambiguous and conglomerate than classical subject-object relations allow. On another, more everyday but no less magical sense, object-touch framed in this way can 
prompt students' recognition of their existence, their biography, as co-implicated with that of the object touched. If the touching of objects is conducive to diffractive learning, this is because touch reveals the mutual embedding of 'subject' and 'object' to be phenomenological as much as it is figurative and discursive.

\section{Conclusion}

Pursuing OBL as less ambiguously a mode of somatic learning, I wish to bring object-based pedagogy into contact with ethically inflected perspectives within the fields of education, posthumanism and post-representational writing. My argument arrives at a pedagogy that is not shy of political encumbrance but instead wants - as Kate Wright says of the Environmental Humanities broadly - to address 'the systemic pathology of a species disconnected from the conditions of its world, [...] challenging delusions of separation [challenging] the erroneous belief that it is somehow possible to exempt ourselves from Earth's ecological community' (2014: 278). Creative Writing, as a set of disciplinary practices whose material performance concretises and reinforces the discourses that give them context, has not been immune to these delusions. While the activities undertaken in our classrooms under the rubric of reflection and reflexivity are demonstrably productive of creative works, Donna Haraway's remarkable scholarship underscores the frequently unmarked complicity between representationalism, reflection and productivism. Moreover, Haraway has gifted a variety of fields - a growing number - with 'diffraction' as a concept with which to counter the material-discursive effects of the persistent representationalist preoccupation, the unevenly disadvantaging impact of which has been noted by feminist and materialist scholars in the humanities and sciences alike. Diffraction - as methodology, as pedagogy, as creative process and written outcome - provides grounds for confronting these disadvantages through creative, writerly action.

\section{Endnotes}

1. I index my discomfort with the use of the shorthand term 'Anthropocene' in this brief article by referring readers to Eileen Crist's nuanced essay, 'On the poverty of our nomenclature' (2013). See also Moore (2015) for a Marxist perspective on the term's deficiencies.

2. Ekphrasis, as a literary mode, may appear to offer a more intuitive entrée to a discussion of the use of objects in writing classrooms than does OBL, given that the former concept has developed from disciplines affiliate with Creative Writing. Yet, the persistent and widely cited definition of ekphrasis - 'verbal representation of a visual representation' (Heffernan, qtd. in Clüver 2017: 30) - runs counter to my purposes. The dominant definition of ekphrasis is as an 'interartistic analogy between poetry and painting' (Bilman 2013: 1). Claus Clüver (2017) emphatically revises the definition to include the verbalization of 'non-kinetic visual configuration' (41), but this also falls short of licensing sensory and haptic sources for ekphrastic engagement, circumscribing ekphrasis as a non-tactile activity. Indeed, not only is the literature on OBL more useful to me here than is the literature on ekphrasis, I would stress the significant potential for research in OBL to vindicate a revision of ekphrasis to include artworks that are not primarily visual.

3. See, though, Stephen Kemmis's outlier contribution to Boud, Keogh and Walker (1985), which diverges from the influential model this book otherwise propounds in its denial of reflection as 'a "purely" internal, psychological process' (141). Rather, it is, he avers, always 'action-oriented and historically embedded' (141). In the discipline of social work, too, the 
concept of 'reflexivity' is parsed into two spheres: psychological activity and the sociopolitical mediation of the psychological activities of reflection and learning (see Bozalek \& Zembylas 2017: 113).

\section{Works Cited}

Alvarado, AE \& PR Herr 2003 Inquiry-based learning using everyday objects: Hands-on instructional strategies that promote active learning in grades 3-8, Corwin Press, Thousand Oaks

Armstrong, K 2009 'Sustaining the unsustainable? Developing a practice and problem-led new media praxis', in H Smith \& R Dean (eds) Practice-led research, research-led practice in the Creative Arts, Edinburgh UP, Edinburgh: 187-199

Bain, JD, R Ballantyne, C Mills \& N C Lester 2002 Reflecting on practice: Student teachers' perspectives, Post Pressed, Flaxton

Barad, KM 2007 Meeting the universe halfway: Quantum physics and the entanglement of matter and meaning, Duke UP, Durham

Barad, KM 2012 'On touching: The inhuman that therefore I am', differences 25, 3: 206-223

Barton, G \& M Ryan 2014 'Multimodal approaches to reflective teaching and assessment in higher education', Higher Education Research \& Development 33, 3: 409-424

Bennett, J 2010 Vibrant matter: A political ecology of things, Duke UP, Durham

Bilman, E 2013 Modern ekphrasis, Peter Lang, New York

Boud, D, R Keogh \& D Walker (eds) 1985 Reflection: Turning experience into learning, Kogan Page, London

Bourke, N \& P Nielsen 2004 'The problem of the exegesis in Creative Writing higher degrees', TEXT Special Issue 3: Illuminating the Exegesis (April): http://www.textjournal.com.au/speciss/issue3/bourke.htm (accessed 1 March 2018)

Bozalek, V \& M Zembylas 2017 'Diffraction or reflection? Sketching the contours of two methodologies in educational research', International Journal of Qualitative Studies in Education 30, 2:111-127

Candlin, F 2010 Art, museums and touch, Manchester UP, Manchester

Chatterjee, H (ed.) 2008 Touch in museums: Policy and practice in object handling., Berg, Oxford \& New York

Chatterjee, H, L Hannan \& L Thomson 2016 'An Introduction to object-based learning and multisensory engagement', in H Chatterjee \& L Hannan (eds) Engaging the senses: Object-based learning in higher education Routledge, New York (eBook): 13-29

Clüver, C 2017 'A new look at an old topic: Ekphrasis revisited', Todas as Letras: Revista de Língua e Literatura 19, 1: 30-44

Crist, E 2013 'On the poverty of our nomenclature', Environmental Humanities 3, 1, 129-147

Dewey, J 1998 [1933] How we think: A restatement of the relation of reflective thinking to the educative process, Houghton Mifflin, Boston

Dooren, T van, E Kirksey \& U Münster 2016 'Multispecies Studies: Cultivating arts of attentiveness', Environmental Humanities 8, 1: 1-23

Dudley, S 2012 Museum objects: Experiencing the properties of things, Routledge: London and New York

Geerts, E and I van der Tuin 2016 'Diffraction \& reading diffractively', New materialism: Almanac 2016/2017: http://newmaterialism.eu/almanac/d/diffraction (accessed 1 March 2018)

Green, $\mathrm{M}$ and T Williams 2018 'On reflection: The role, mode and medium of the reflective component in practice as research', TEXT 22, 1 (April): http://www.textjournal.com.au/aprill18/green_williams.htm (accessed 22 May 2018)

Grossman, R 2008 ‘Structures for facilitating student reflection’, College Teaching 57, 1: 15-22 
Haraway, D 1992 'The promises of monsters: A regenerative politics for inappropriate/d others', in L Grossberg, C Nelson \& PA Treichler (eds) Cultural Studies, Routledge, New York: 295-337

Haraway, D 2000 How like a leaf: An interview with Thyrza Nichols Goodeve, Routledge, New York

Haseman, B \& D Mafe 2009 'Acquiring know-how: Research training for practice-led researchers', in H Smith $\&$ RT Dean (eds) Practice-led research, research-led practice in the Creative Arts, Edinburgh UP, Edinburgh: 211-228

Hein, GE 2009 [1998] Learning in the museum, $2^{\text {nd }}$ edn, Routledge, New York

Hengel, L van den 2012 'Zoegraphy: Per(forming) human lives', Biography, 35, 1: 1-20

Iovino, S \& S Oppermann 2014 Material ecocriticism, Indiana UP, Bloomington (eBook)

Jarvis, P 1995 [1983] Adult and continuing education: Theory and practice, $2^{\text {nd }}$ edn, Routledge, New York

Kalantzis, M \& B Cope 2008 New learning: Elements of a science of education, Cambridge UP, Cambridge

Kemmis, S 1985 'Action research and the politics of reflection', in D Boud, R Keogh \& D Walker (eds)

Reflection: Turning experience into learning, Kogan Page, London: 139-164

Kirby, V 2011 Quantum anthropologies: Life at large, Duke UP, Durham

Kolb, D \& R Fry 1975 'Toward an applied theory of experiential learning', in C Cooper (ed.) Theories of group process, John Wiley, London: 33-48

Mathews, J 1998 'Somatic knowing and education', The Educational Forum 62, 3: 236-242

Mauthner, N 2016 'Diffractive genealogies', New materialism: Almanac 2016/2017:

http://newmaterialism.eu/almanac/d/diffraction. (accessed 1 March 2018)

McHugh, N 2007 Feminist philosophies A-Z, Edinburgh UP, Edinburgh

Meecham, P 2016 'Talking about things: Internationalisation of the curriculum through object-based learning', in H Chatterjee \& L Hannan (eds) Engaging the senses: Object-based learning in higher education, Routledge, New York (eBook): 66-81

Moon, $\mathrm{J} 2004$ A handbook of reflective and experiential learning: Theory and practice, RoutledgeFalmer, New York \& London

Moore, JW 2016 Anthropocene or capitalocene? Nature, history, and the crisis of capitalism, PM Press/Kairos, Oakland

Neimanis, A 2017 'Nature represents itself: Bibliophilia in a changing climate', in V Kirby (ed.) What if culture was nature all along? Edinburgh UP, Edinburgh: 179-198

Rozynski, K 2012 'The writing body and the reading sensorium: material calibrations of a living encounter', in Encounters: place, situation, context: Refereed proceedings of the 17th Conference of the Australasian Association of writing Programs: http://www.aawp.org.au/publications/the-encounters-place-situation-contextpapers/ (accessed 1 March 2018)

Rozynski, K 2015 'Assembling bodies: A new materialist approach to writing practice', Axon: Creative Explorations 5, 2: http://www.axonjournal.com.au/issue-9/assembling-bodies (accessed 1 March 2018)

Ryan, M 2013 'The pedagogical balancing act: Teaching reflection in higher education', Teaching in Higher Education 18, 2, 144-155

Ryan, M \& M Ryan 2012 'Theorising a model for teaching and assessing reflective learning in higher education', Higher Education Research and Development 32, 2: 244-257

Sansone, C \& JM Harackiewicz 2000 'Controversies and new directions - is it deja vu all over again?', in C Sansone \& JM Harackiewicz (eds) Intrinsic and extrinsic motivation: The search for optimal motivation and performance, Academic Press, San Diego: 444-454

Smith, H \& RT Dean 2009 'Introduction: Practice-led research, research-led practice. Towards the iterative cyclic web', in H Smith \& R T Dean (eds) Practice-led research, research-led practice in the Creative Arts, Edinburgh UP, Edinburgh: 1-38 
Smith, MK 2001 'David A. Kolb on experiential learning', in The encyclopaedia of informal education, YMCA George Williams College: http://infed.org/mobi/david-a-kolb-on-experiential-learning/ (accessed 1 March 2018)

Snaza, N, D Sonu, SE Truman \& Z Zaliwska (eds) 2016 Pedagogical matters: New materialisms and curriculum studies, Peter Lang, New York

Somerville, M, P de Carteret, B Davies, S Gannon \& K Power (eds) 2011 Place pedagogy change, SensePublishers, Rotterdam

Taylor, A, V Pacini-Ketchabaw, S de Finney \& M Blaise 2016 'Inheriting the ecological legacies of settler colonialism', Environmental Humanities 7, 1: 129-132

Wright, K 2014 'Becoming-with', Environmental Humanities 5, 1: 277-281 